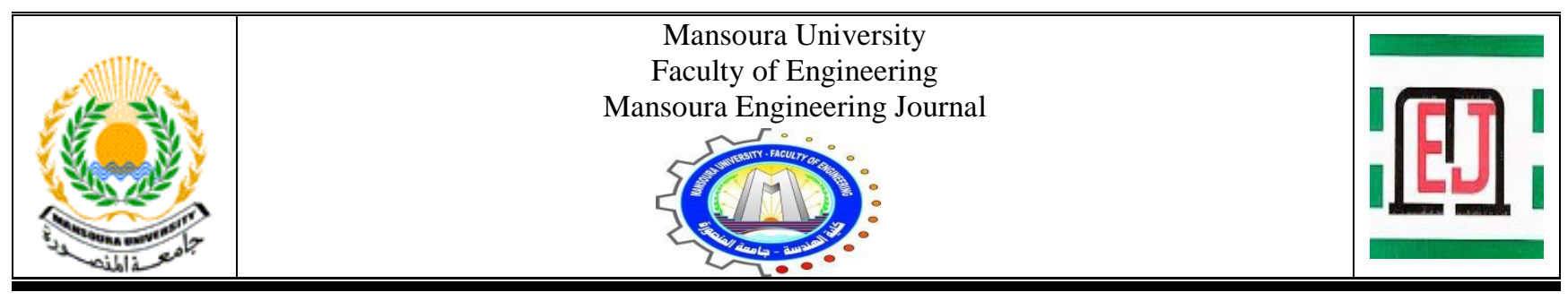

\title{
Developing a Mathematical Model to Evaluate Asphalt Pavement Condition for Libyan Roads
}

\author{
Elmustafa F. Elawkali*, Hassan A. Mahdy, Hamdy E. Mohamed and Ahmed A. Soliman
}

\begin{abstract}
Pavement evaluation is a very important step for pavement preservation. The researcher suggests a technique for evaluating the flexible pavement in Libya. Due to the absence of an approved method by the Libyan government. To obtain appropriate data, this study used indices of pavements evaluation such as Pavement Condition Index (PCI), International Roughness Index (IRI) and Present Serviceability Index (PSI). and investigated their correlation with the Libyan Road Users' Opinion (LRUO). The data showed that PSI has a moderate correlation with LRUO, IRI did not show agreement with LRUO, but it indicated a strong relationship between the LRUO and PCI with a correlation coefficient of 0.807 and $R$ square 0.652 . Moreover, the relations of PCI with other evaluation methods are strong with a correlation coefficient of 0.828and -0.734 for PSI and IRI. Also, develop a PCI model according to LRUO and IRI with R square 0.95 Standard error 8.9 Thus, the PCI can be determined more quickly and simply through LRUO and IRI. Finally, developed an arithmetic model for the Libyan roads pavement index (LRPI), based on PCI and IRI with R square 0.901 stander error of estimated 0.45 .
\end{abstract}

\section{INTRODUCTION}

$\mathrm{T}$ THE transportation system occupies a special part in the economic growth of any state. Safe, comfortable, and fast transportation systems allow people to connect safely and fast, and ease goods

Received: (18 March, 2021) - Revised: (10 June, 2021) - Accepted: (30 June, 2021)

*Corresponding Author: E. F. Elawkali Master student of Highway and Traffic Engineering, Public Works Department, Faculty of Engineering, Ain Shams University, 1 El-Sarayat street, Abbassia,11381, Cairo, Egypt (email: aalawkali@gmail.com ).

H. A. Mahdy, Professor of Highway and Traffic Engineering, Public Works Department, Faculty of Engineering, Ain Shams University, 1 ElSarayat street, Abbassia,11381, Cairo, Egypt. (email: hassan_mahdy@eng.asu.edu.eg).

H. E. Mohamed Assistant Professor of Highway and Traffic Engineering, Public Works Department, Faculty of Engineering, Ain Shams University, 1 El- Sarayat street, Abbassia,11381, Cairo, Egypt (email: hamdy.ibrahim@eng.asu.edu.eg).

A. A. Soliman Assistant Professor of Highway and Traffic Engineering, Public Works Department, Faculty of Engineering, Ain Shams University, 1 El-Sarayat street, Abbassia,11381, Cairo, Egypt (email: ahmedatef87@eng.asu.edu.eg). distribution in the country [1].

Highways are one of the major transportation systems in the history of mankind as the construction of roadways was an essential part of several civilizations and empires [2]. In addition, highway systems promote the transportation of passengers and goods by providing vital networks between various areas. The importance of roadways in any country increases according to its geographical location [3], especially in the absence of other transportation systems such as railways and water transport.

On other hand, like other types of infrastructure assets, pavements deteriorate over time. For these reasons, it is necessary to preserve pavements to guarantee their performances during their lifetime [4]. In recent years and due to limited resources, many countries tend to maintain and 
rehabilitate (preserve) their road networks instead of constructing new ones.

The first step for pavement preservation is to determine the functional and structural conditions of a highway section. Functional condition is concerned with the ride quality or safety aspects of a highway section [5], whereas the structural evaluation is concerned with the road deflection value and the structural material [6]. This process is known as pavement evaluation. Different methodologies are used for pavement evaluation such as pavement condition index (PCI), present serviceability index (PSI), and international roughness index (IRI), ... etc. Pavement evaluation helps to assign a preservation strategy for the existing pavements [7].

Unlike the methods that are globally used for pavement evaluation, visual inspection and local experience are used in Libya for pavement evaluation. Unfortunately, Libya suffers from the absence of pavement management systems that use the appropriate means for data collection and data analysis [8]

The main objective of this study is to propose a simple, appropriate, quick, and inexpensive methodology that can be used for pavement evaluation for Libyan roads that helps optimizing resources to achieve the best pavement performances.

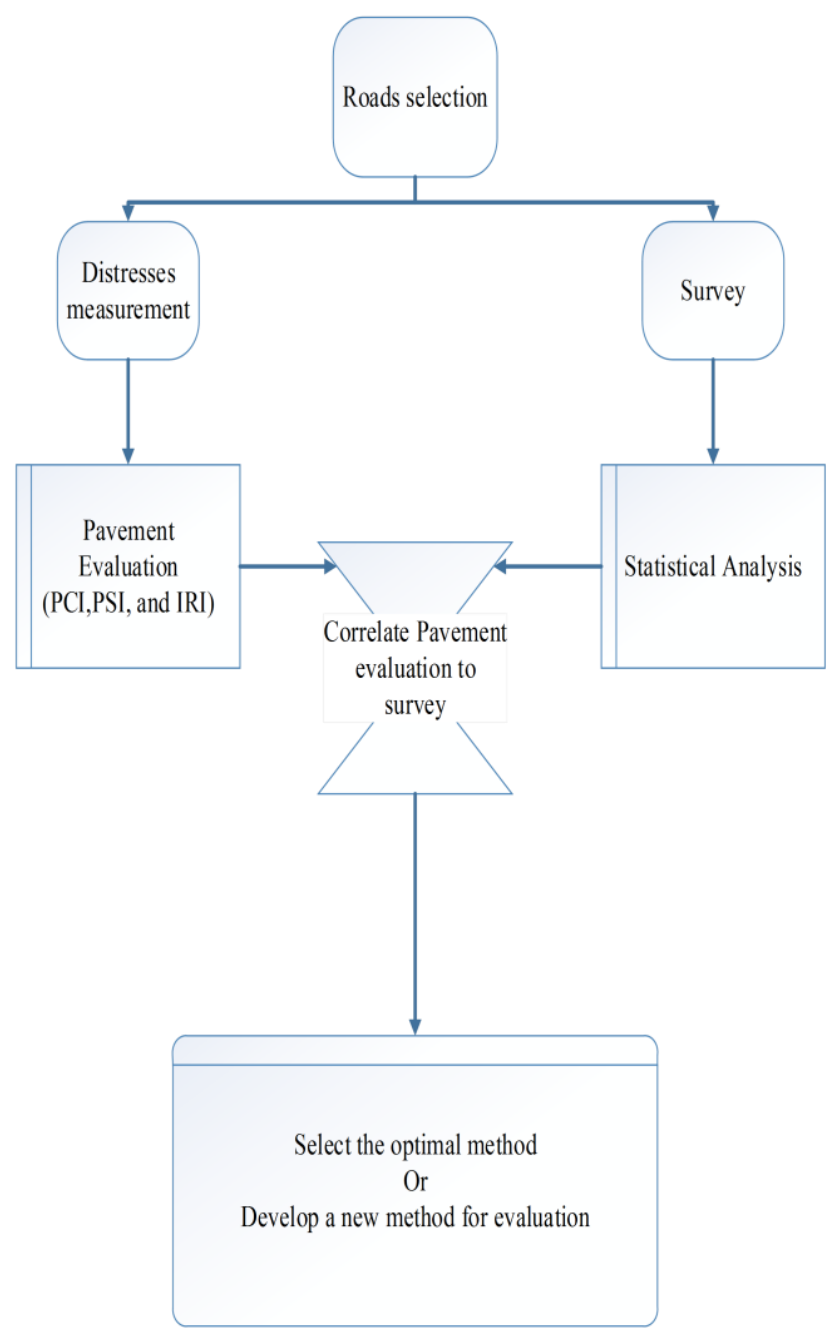

fig. 1 methodology flowchart
To reach this goal, a flow chart was prepared that explains the research methodology as shown in Figure 1.

\section{LITERATURE REVIEW}

In recent years, many studies aimed to find relationships between different pavement evaluation methods. Some of these papers depended on findings from their own data, while others imported data from Long-Term Pavement Performance (LTPP)database.

For example, Piryonesi\&El-diraby used LTPP data for over 61 different states to study the relationship between IRI and PCI; weak correlation with $\mathrm{R}^{2}$ of 0.302 was found.

$$
I R I=2.064-0.012 P C I \quad R^{2}=0.302
$$

Then the data were clustered into more meaningful groups based on location (province/state). Data grouping helped increasing the $\mathrm{R}^{2}$ value up to 0.70.[9]

Likewise, Elhadidy used LTPP data to find a relationship between PCI and IRI with $\mathrm{R}^{2}$ of 0.995 . The model validation using a different dataset also yielded highly accurate predictions $(\mathrm{R} 2=0.992)$. [10]

In Iraq, two models between IRI and PCI were developed by Abed; Dynatest Road Surface Profiler was applied to collect pavement roughness data, and a visual inspection used the PCI. Linear and nonlinear regressions have been used for developing these models which have $\mathrm{R} 2$ equal to 0.715 and 0.722 for linear and quadratic models.[11]

In Medan City (Indonesia), Hasibuan \& Surbakti developed an exponential relationship between PCI and IRI with R square of 0.59 by using Bina Marga IRI data and PCI (ASTM D 6433). [12] However, this was not the first research used for user opinion to evaluate pavement conditions.

In 1960, the Present Serviceability Index (PSI) was defined as a user-based performance measure to define pavement quality and failure at the AASHO Road-test was developed by [13]. Hudson used the same approach in creating their Riding Comfort Index, but on a 0 to 10 scale [14]

Psychometric scaling analysis was used to develop a set of IRI threshold values for classifying road condition based on public perception in the Province of Alberta (Western Canada) by Tehrani\&Mesher [15]. According to the results of the survey, Alberta Transportation threshold values of IRI do not agree with the road users' opinion. As well, Hudson, et al results show that PSI is tied to road user response, but IRI is not. It contends that PSI can serve all levels of need while IRI does not, because it is not understood by highway users and legislators. PSI reflects human rider response and IRI does not close that gap [14]. on the other hand, Kadhim \& Mahdi showed that the users' opinions of the studied road in Diwaniyah city (Iraq) were affected mainly by the roughness of the roads, while distresses such as cracks, potholes and rutting have an insignificant effect. [16]

\section{METHODOLOGY}

The following steps were followed to develop a mathematical model to evaluate the flexible pavement in east Libya: 
- A sample of Libyan highways was selected. All highways were paved using hot mix asphalt (HMA).

- Survey data from Libyan's road user's opinion LRUO for highways quality in scale from 0 to 10 was collected

- The IRI was measured for all selected highways using smartphone application.

- Asphalt Distresses were measured for all roads. PCI and PSI indices were calculated.

- Pearson correlation matrix between PCI, IRI, and PSI, and LRUO were calculated

- A new mathematical model between LRUO the best significant correlation matrix was proposed.

\section{A. Roads Selection}

The sample was chosen to represent different climates in Libya. However, no samples were taken from the far south, and western Libya due to the security situation. Roads were selected so that that the beginning and end of each road sample is a stopping point, such as gas stations, rest stops and checkpoints...etc. so that surveyors can collect the survey from the road users. Fig.2 and Table1 shown all information of roads

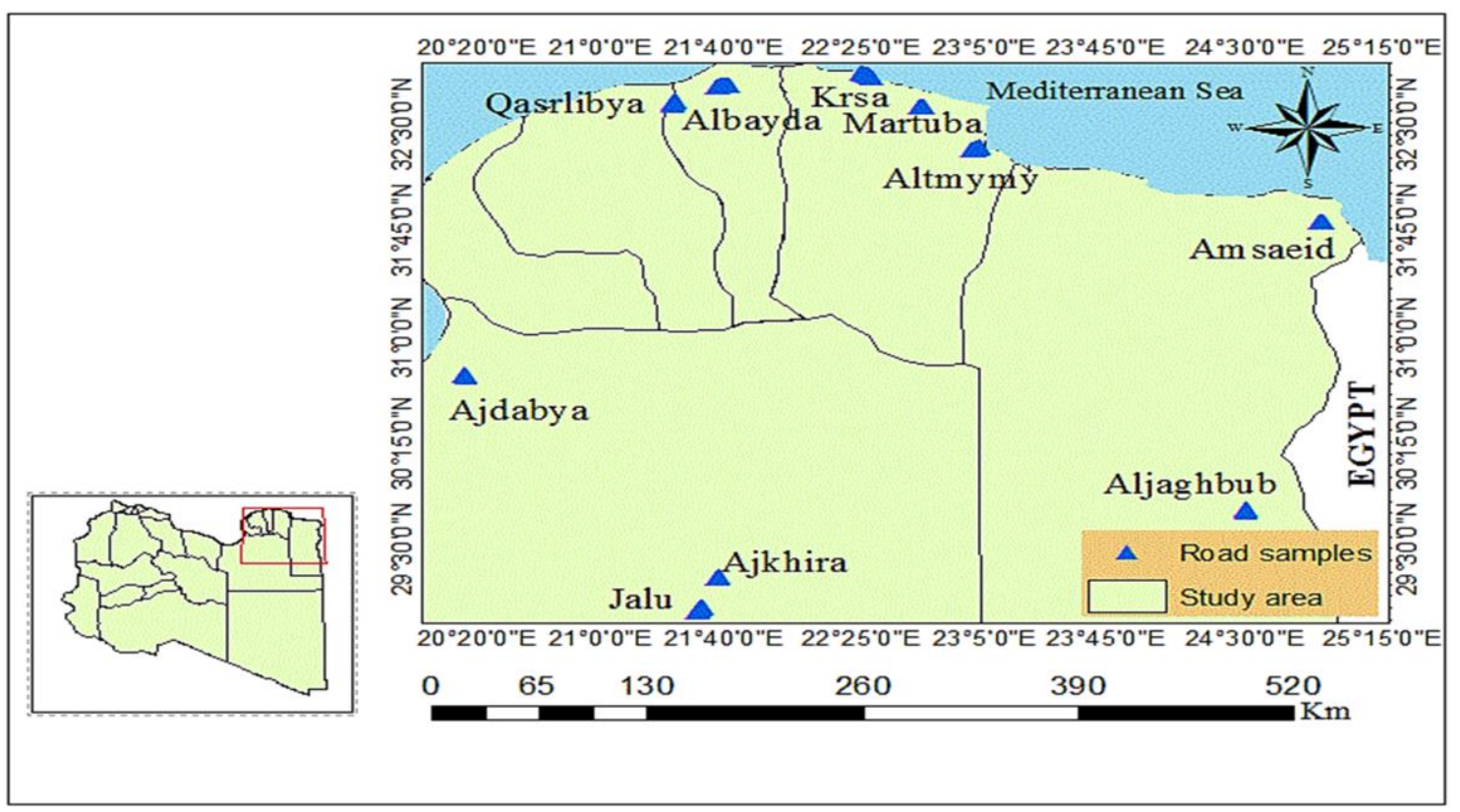

fig. 2 study area location

TABLE 1

ROAD SAMPLE DEFINITION

\begin{tabular}{|c|c|c|c|}
\hline Road name & Lengths(km) & Section ID & $\begin{array}{c}\text { Link between } \\
\end{array}$ \\
\hline \multirow[t]{2}{*}{ Aljaghbub } & \multirow[t]{2}{*}{2.534} & 1-D1 & Abu Hashim supermarket-Gas station 011 \\
\hline & & 1-D2 & Gas station 011-Abu Hashim supermarket \\
\hline \multirow[t]{2}{*}{ Ajdabya } & \multirow[t]{2}{*}{1.93} & $2-\mathrm{D} 1$ & Gas station $881-$ Ajdabya gate \\
\hline & & $2-\mathrm{D} 2$ & Ajdabya gate-Gas station 881 \\
\hline \multirow[t]{2}{*}{ Jalu } & \multirow[t]{2}{*}{5.18} & 3-D1 & Al Jazeera neighbourhood- Jakherra neighbourhood \\
\hline & & 3-D2 & Jakherra neighbourhood- \\
\hline \multirow{2}{*}{ Jakherra } & \multirow[t]{2}{*}{1.78} & 4-D1 & Faculty of Energy Techniques- Cultural Center \\
\hline & & 4-D2 & Cultural Center-Faculty of Energy Techniques \\
\hline \multirow[t]{2}{*}{ Qasrlibya } & \multirow[t]{2}{*}{6.436} & 5-D1 & Qasrlibya police station-elzawiya sonosy \\
\hline & & 5-D2 & Elzawiya sonosy-Qasrlibya police station \\
\hline \multirow[t]{2}{*}{ Krsa } & \multirow[t]{2}{*}{6.851} & 6-D1 & Krsa gate- elabas Mosque \\
\hline & & 6-D2 & elabas Mosque-Krsa gate \\
\hline \multirow[t]{2}{*}{ Martuba } & \multirow[t]{2}{*}{2.3} & 7-D1 & Martuba gate-Gas st of Road Services Company \\
\hline & & 7-D2 & Gas st of Road Services Company-martuba gate \\
\hline \multirow[t]{2}{*}{ Altmymy } & \multirow[t]{2}{*}{4.997} & 8-D1 & Altmymy gate-Qweder gas station \\
\hline & & $8-\mathrm{D} 2$ & Qweder gas station-altmymy gate \\
\hline \multirow[t]{2}{*}{ Albayda } & \multirow[t]{2}{*}{7.1} & 9-D1 & Albayda gate-Masa gate \\
\hline & & 9-D2 & Masa gate- Albayda gate \\
\hline \multirow[t]{2}{*}{ Amsaeid } & \multirow[t]{2}{*}{2} & 10-D1 & Eldayim gas station-Am rokba police station \\
\hline & & $10-\mathrm{D} 2$ & Am rokba police station-eldayim gas station \\
\hline
\end{tabular}




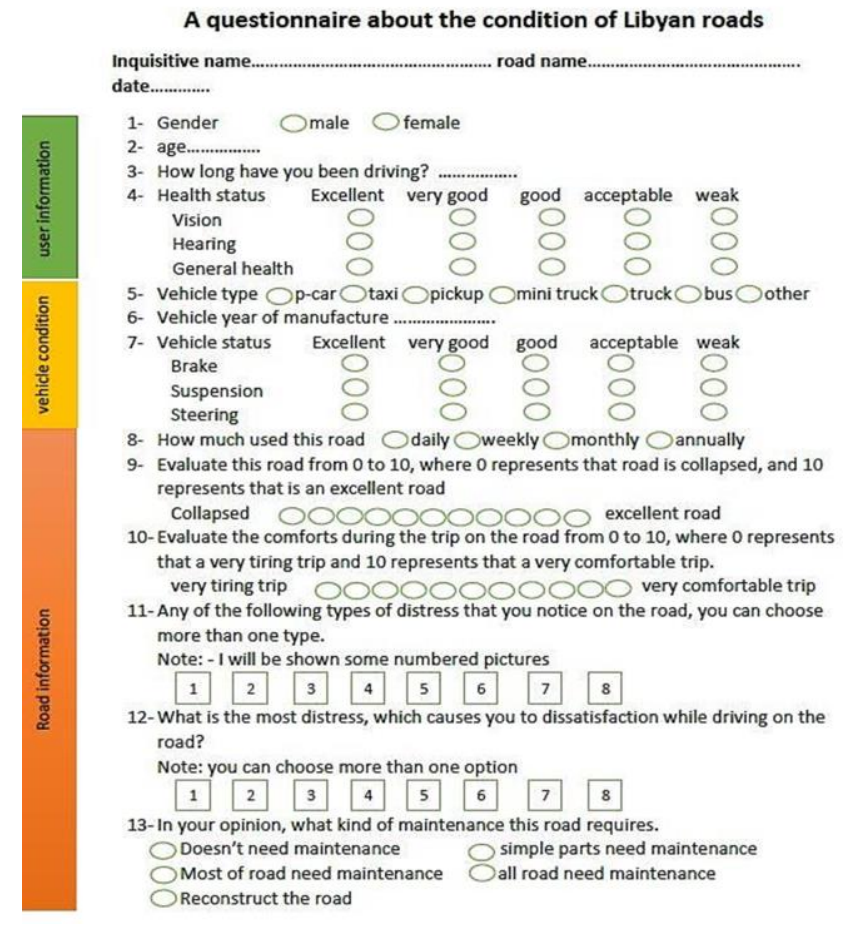

Fig. 3 Questionnaire form

\section{B. The Survey}

A questionnaire/survey was prepared from thirteen questions, which is divided into three sections that describe the type of questions.

The first section of the survey considers the personal information of the road user (gender, age, driving experience, and health status). The second section is specific to the vehicle information (vehicle type, year of manufacture, and vehicle condition). Finally, the third section consists of six questions inquiring about the road conditions, as shown in Fig.3. for each section, 50 questionnaires were collected.

\section{Distress Measurement}

Distress data was measured based on instructions of the Distress Identification Manual (DIM) of The Long-Term Pavement Performance Program (LTPP). This procedure has been adopted by the American Association of State Highway and Transportation Officials (AASHTO) and the Federal Highway Administration (FHWA) [17].

For each road, distresses were defined by their type, area, and severity level. Each road was divided into sections, where every section was 100 meters. The type of distresses that were collected during this study is shown in Table 2 .
TABLE 2

ROAD DISTRESS MEASUREMENT GUIDE [18]

\begin{tabular}{|c|c|c|c|}
\hline $\begin{array}{l}\text { Distress } \\
\text { group }\end{array}$ & Distress type & $\begin{array}{c}\text { Measurement } \\
\text { unit }\end{array}$ & $\begin{array}{c}\text { Severity } \\
\text { level }\end{array}$ \\
\hline \multirow{5}{*}{ Cracking } & $\begin{array}{l}\text { Alligator } \\
\text { cracking }\end{array}$ & $m^{2}$ & $\begin{array}{l}\text { Low, } \\
\text { Medium, } \\
\text { High }\end{array}$ \\
\hline & $\begin{array}{l}\text { Block } \\
\text { cracking }\end{array}$ & $m^{2}$ & $\begin{array}{l}\text { Low, } \\
\text { Medium, } \\
\text { High }\end{array}$ \\
\hline & $\begin{array}{l}\text { Longitudinal } \\
\& \text { transverse }\end{array}$ & $\mathrm{m}$ & $\begin{array}{l}\text { Low, } \\
\text { Medium, } \\
\text { High }\end{array}$ \\
\hline & Edge cracking & $\mathrm{m}$ & $\begin{array}{l}\text { Low, } \\
\text { Medium, } \\
\text { High }\end{array}$ \\
\hline & $\begin{array}{l}\text { Joint } \\
\text { reflection } \\
\text { cracking }\end{array}$ & $\mathrm{m}$ & $\begin{array}{l}\text { Low, } \\
\text { Medium, } \\
\text { High }\end{array}$ \\
\hline Patching & Patching & $m^{2}$ & $\begin{array}{l}\text { Low, } \\
\text { Medium, } \\
\text { High }\end{array}$ \\
\hline \& Potholes & Potholes & Number \& $m^{2}$ & $\begin{array}{l}\text { Low, } \\
\text { Medium, } \\
\text { High }\end{array}$ \\
\hline Surface & Rutting & $m^{2}$ & $\begin{array}{l}\text { Low, } \\
\text { Medium, } \\
\text { High }\end{array}$ \\
\hline Deformation & Shoving & $m^{2}$ & $\begin{array}{l}\text { Low, } \\
\text { Medium, } \\
\text { High }\end{array}$ \\
\hline \multirow{3}{*}{$\begin{array}{l}\text { Surface } \\
\text { Defects }\end{array}$} & Bleeding & $m^{2}$ & $\begin{array}{l}\text { Low, } \\
\text { Medium, } \\
\text { High }\end{array}$ \\
\hline & Raveling & $m^{2}$ & $\begin{array}{l}\text { Low, } \\
\text { Medium, } \\
\text { High }\end{array}$ \\
\hline & $\begin{array}{l}\text { Polished } \\
\text { aggregate }\end{array}$ & $m^{2}$ & $N / A$ \\
\hline \multirow[t]{2}{*}{ Miscellaneous } & $\begin{array}{l}\text { Lane to } \\
\text { shoulder drop- } \\
\text { off }\end{array}$ & $\mathrm{m}$ & $\begin{array}{l}\text { Low, } \\
\text { Medium, } \\
\text { High }\end{array}$ \\
\hline & $\begin{array}{l}\text { Water } \\
\text { bleeding \& } \\
\text { pumping }\end{array}$ & $\mathrm{m}$ & $N / A$ \\
\hline
\end{tabular}

\section{Pavement Condition Index Determination}

The PCI was calculated using the MICROPAVER5.2 (EMS)software, which was originally developed in the late 1970s to aid the Department of Defense (DOD) manage Maintenance and Rehabilitation (M\&R) for its enormous inventory of pavements. MICROPAVER uses PCI in accordance with ASTM D 6433. The output from this software is the pavement condition index (PCI) rating from zero (failed) to 100 (excellent) for consistently describing a pavement's condition and for predicting its $M \& R$ needs many years into the future [18].

\section{E. International Roughness Index Measurement}

International Roughness Index (IRI) is a widely used pavement performance measure collected with specially equipped vehicles; however, the cost of data collection may limit the ability of some road authorities to procure the data. 
Recent advances in smartphone technology have created interest in their potential to be low-cost mobile data collection platforms [19].

The principles behind the IRI measurement system by smartphone are simply by use of several sensors embedded in smartphones such as a gyroscope, 3-axis accelerometers, and a Global Positioning System GPS.

The IRI data collection technology for this project was developed by TotalPave Inc. The principles behind the TotalPave system are explained in Cameron (2014). It is calibrated against the standard profiler using different types of smartphones and vehicles [20]. The TotalPave data collection process is fully automated. The user needs to mount a smartphone with a TotalPave IRI Calculator app to the vehicle's windshield. IRI for each road section, defined by 100-m, was measured using TotalPave

\section{F. Present Serviceability Index calculation}

The current PSI for a given section of flexible highway can be calculated from the average slope variance, average rut depth, and cracking and patching, in accordance with AASHO Road Test Report 5 [20]. The equation can be written as shown in (1).

$$
\begin{aligned}
& P S I=5.03-1.91 \log (1+\overline{S V})-1.38\left(\overline{R D^{2}}\right)- \\
& 0.01 \sqrt{(P+C)}
\end{aligned}
$$

$$
\overline{S V}=2.2704 I R I^{2}
$$

SV: average slope variance from both wheel paths

IRI: international roughness index $(\mathrm{m} / \mathrm{km})$

RD: average rut depth from both wheel paths based on a 4 $\mathrm{ft}(1.22 \mathrm{~m})$ straight edge, in inches

$\mathrm{C}$ : square feet of Class 2 and Class 3 cracking per $1,000 \mathrm{ft} 2$ (92.9 m2); and

P: patching in square feet per 1,000 ft2 $(92.9 \mathrm{~m} 2)$.

The relationship between the international roughness index and slope variance (2) [21] was used to calculate (SV).

\section{RESULTS AND DISCUSSION}

PCI, PSI, IRI, and LRUO shown in Table 3 results were input in SPSS software to determine their Pearson correlation. The value of LRUO is the average results obtained from question 9 in the questionnaire, which represents road users' opinion of the Libyan road about flexible pavement evaluation, ranges from 0 , which represents the worst condition of the road, to 10 , which represents that the best condition. 50 responses were taken from users for each section, and then averaged the answers and compared with PCI, IRI and PSI for each section.

TABLE 3

DATA INPUT

\begin{tabular}{l||l||l||l||l} 
Road name & Average LRUO & Average PCI & $\begin{array}{l}\text { Average IRI } \\
(\mathbf{m} / \mathbf{k m})\end{array}$ & Average PSI \\
\hline Aljaghbub & 2.18 & 15.81 & 3.06 & 1.52 \\
\hline Ajdabya & 5.02 & 84.30 & 1.72 & 3.34 \\
\hline Jalu & 4.76 & 29.75 & 5.48 & .88 \\
\hline Ajkhira & 4.96 & 28.44 & 5.86 & 1.29 \\
\hline Qaserlibya & 5.02 & 89.26 & 1.93 & 2.95 \\
\hline Krsa & 6.10 & 84.00 & 3.25 & 2.11 \\
\hline Martuba & 6.80 & 93.43 & 2.80 & 2.60 \\
\hline Altmymy & 6.10 & 88.36 & 1.82 & 3.08 \\
\hline Albayda & 5.56 & 96.21 & 2.12 & 2.42 \\
\hline Amsaeid & 6.16 & 95.05 & 1.34 & 3.52
\end{tabular}

\section{A. Variables Correlations}

As shown in Table 4, Pearson correlation matrix, a strong positive correlation was found between the LRUO and PCI with a correlation coefficient of 0.807 , and a significant level of 0.01. Also, a moderate positive relationship was found between LRUO and PSI with a correlation coefficient of 0.492 , but it is not significant. Finally, a weak negative relationship was found between LRUO and IRI with a correlation coefficient of 0.254 , and not significant.

Furthermore, a strong relationship was found between the PCI and IRI with a correlation coefficient of -0.734 , PCI and PSI with a correlation coefficient of 0.828. Linear relationships were drawn between all the variables and are shown in Fig.4. 
TABLE 4

PEARSON CORRELATION MATRICS

\begin{tabular}{|c|c|c|c|c|}
\hline Correlations & LRUO & PCI & IRI & PSI \\
\hline \multirow{2}{*}{$\begin{array}{l}\text { LRUO Pearson Correlation } \\
\text { Sig. (2-tailed) }\end{array}$} & 1 & $0.807 * *$ & -0.254 & 0.492 \\
\hline & - & 0.005 & 0.479 & 0.149 \\
\hline \multirow{2}{*}{$\begin{array}{l}\text { PCI Pearson Correlation } \\
\text { Sig. (2-tailed) }\end{array}$} & $0.807^{* *}$ & 1 & $-0.734 *$ & $0.828 * *$ \\
\hline & 0.005 & - & 0.016 & 0.003 \\
\hline \multirow{2}{*}{$\begin{array}{l}\text { IRI Pearson Correlation } \\
\text { Sig. (2-tailed) }\end{array}$} & -0.254 & $-0.734 *$ & 1 & $-0.911 * *$ \\
\hline & 0.479 & 0.016 & - & 0.000 \\
\hline \multirow{2}{*}{$\begin{array}{l}\text { PSI Pearson Correlation } \\
\text { Sig. (2-tailed) }\end{array}$} & 0.492 & $0.828 * *$ & $-0.911 * *$ & 1 \\
\hline & 0.149 & 0.003 & 0.000 & - \\
\hline
\end{tabular}

**. Correlation is significant at the 0.01 level (2-tailed).

*. Correlation is significant at the 0.05 level (2-tailed).

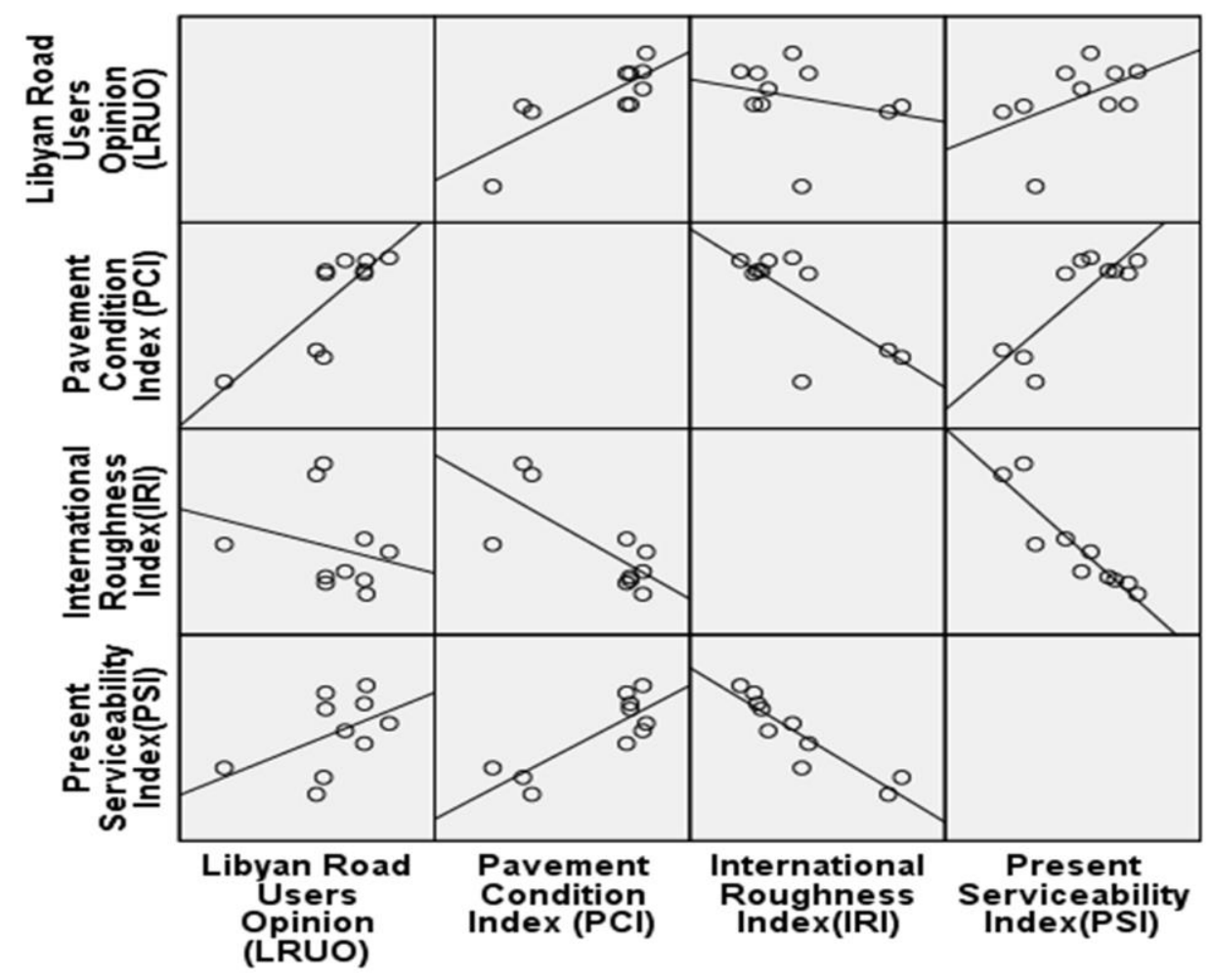

fig. 4 Linear regression matrix for all variables

\section{B. Linear Regression Model}

Regression analysis was used to develop a mathematical model that best correlates LRUO to different pavement evaluation indices. The linear regression model was applied to the variables, to find a relationship describing PCI (dependent variable) based on the rest of the independent variables as the PCI showed the highest correlation with LRUO.

As showing in Table 5 two relationships that represent PCI were obtained as follows:

$$
\begin{aligned}
& P C I(\text { estimated })=20.840 \text { LRUO }-39.041 \\
& P C I(\text { estimated })=17.132 \text { LRUO }-11.1885 \text { IRI }+ \\
& 15.404
\end{aligned}
$$

PCI (estimated): Pavement Condition Index it's an estimated value of pavement condition depends on Libyan road users' opinions LRUO.

Model 1, obtained from equation 3, has a large stander error (20.60) and coefficient of determination (0.652), whilst model 2 , obtained from equation 4 , has a lower stander error 
(8.24) and higher coefficient of determination (0.937).

In model 1, there is a significant effect of LRUO on PCI at the $\mathrm{p}<0.01$ level for the three conditions $[\mathrm{F}(1,8)=14.956$, $\mathrm{P}$ $=0.005]$. whilst in model 2 , there is a significant effect of
LRUO and IRI on PCI at the $\mathrm{p}<0.01$ level for the three conditions $[\mathrm{F}(2,7)=68.210, \mathrm{P}=0.000]$. according to ANOVA test results shown in Table 6.

TABLE 5

MODELS SUMMARY

\begin{tabular}{|c|c|c|c|c|c|c|c|c|c|c|}
\hline & \multirow[t]{2}{*}{ Model } & \multicolumn{2}{|c|}{$\begin{array}{l}\text { Unstandardized } \\
\text { Coefficients }\end{array}$} & $\begin{array}{c}\text { Standardized } \\
\text { Coefficients }\end{array}$ & \multirow[t]{2}{*}{$\mathbf{t}$} & \multirow[t]{2}{*}{ Sig. } & \multirow[t]{2}{*}{$\mathbf{R}$} & \multirow[t]{2}{*}{ R Square } & \multirow[t]{2}{*}{$\begin{array}{l}\text { Adjusted } \\
\text { R Square }\end{array}$} & \multirow[t]{2}{*}{$\begin{array}{l}\text { Std. Error of the } \\
\text { Estimate }\end{array}$} \\
\hline & & B & Std. Error & Beta & & & & & & \\
\hline \multirow[t]{2}{*}{1} & \multirow{2}{*}{$\begin{array}{l}\text { (Constant) } \\
\text { LRUO }\end{array}$} & \multirow{2}{*}{$\begin{array}{l}-39.041 \\
20.840\end{array}$} & \multirow{2}{*}{$\begin{array}{l}29.115 \\
5.389\end{array}$} & \multirow[b]{2}{*}{0.807} & -1.341 & 0.217 & \multirow{2}{*}{$\begin{array}{l}0.80 \\
7 \mathrm{a}\end{array}$} & \multirow[t]{2}{*}{0.652} & \multirow[t]{2}{*}{0.608} & \multirow[t]{2}{*}{20.60670} \\
\hline & & & & & 3.867 & 0.005 & & & & \\
\hline & \multirow{3}{*}{$\begin{array}{l}\text { (Constant) } \\
\text { LRUO } \\
\text { IRI }\end{array}$} & \multirow{3}{*}{$\begin{array}{l}15.404 \\
17.132 \\
-11.885\end{array}$} & \multirow{3}{*}{$\begin{array}{l}14.306 \\
2.229 \\
1.813\end{array}$} & \multirow{3}{*}{$\begin{array}{l}0.664 \\
-0.566\end{array}$} & 1.077 & 0.317 & \multirow{3}{*}{$\begin{array}{l}0.97 \\
5 b\end{array}$} & \multirow[t]{3}{*}{0.951} & \multirow[t]{3}{*}{0.937} & \multirow[t]{3}{*}{8.24430} \\
\hline & & & & & 7.686 & 0.000 & & & & \\
\hline & & & & & -6.556 & 0.000 & & & & \\
\hline
\end{tabular}

\begin{tabular}{|c|c|c|c|c|c|c|}
\hline & & & $\begin{array}{l}{ }^{\circ} \mathrm{TAl} \\
\mathrm{AO}\end{array}$ & & & \\
\hline & Model & Sum of Squares & df & Mean Square & $\mathbf{F}$ & Sig. \\
\hline 1 & Regression & 6351.011 & 1 & 6351.011 & 14.956 & $0.005^{\mathrm{b}}$ \\
\hline & Residual & 3397.089 & 8 & 424.636 & & \\
\hline & Total & 9748.100 & 9 & & & \\
\hline 2 & Regression & 9272.320 & 2 & 4636.160 & 68.210 & $0.000^{c}$ \\
\hline & Residual & 475.780 & 7 & 67.969 & & \\
\hline & Total & 9748.100 & 9 & & & \\
\hline
\end{tabular}

a. Dependent Variable: PCI1

b. Predictors: (Constant), LROU1

c. Predictors: (Constant), LROU1, IRI1

Referring to Fig.5 and Fig.6, it can be noticed that model 2 shows a higher correlation than model 1. As a result, pavement evaluation for Libyan roads can be determined from PCI calculations as well as the IRI values obtained from smartphone applications as follows:

$$
L R P I=0.052 P C I+0.598 I R I-0.182
$$

where LRPI is Libyan road pavement index

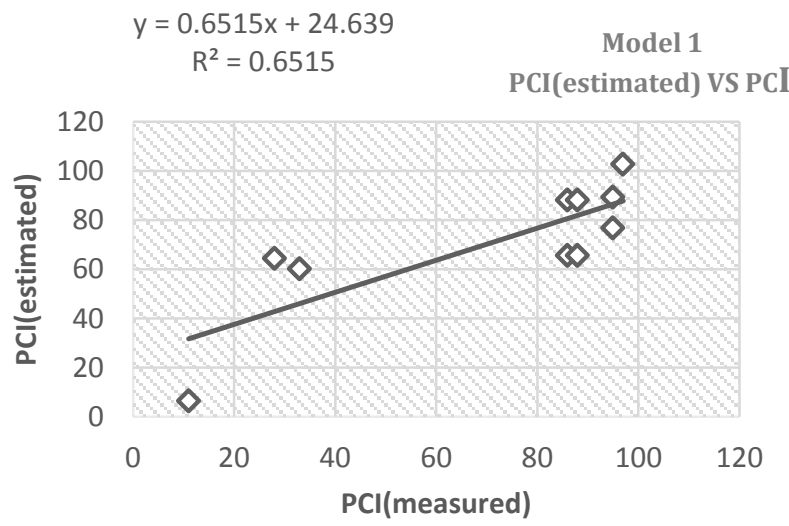

Fig. 5 relationship between predict and observe value of model 1.

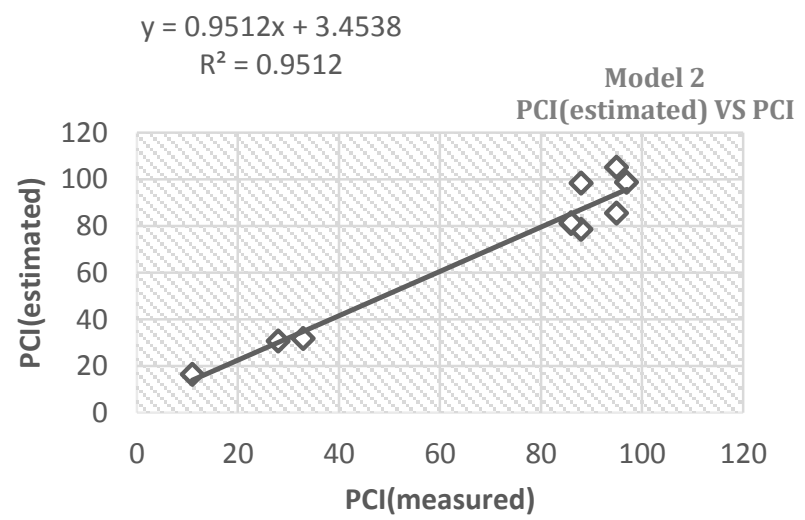

Fig. 6 relationship between predict and observe value of model 2 .

\section{CONCLUSIONS AND RECOMMENDATIONS}

According to the results, conclusions and recommendations can be summarized as follows:

1. PSI and IRI showed moderate correlation with LRUO, while PCI showed a higher correlation.

2. A mathematical model obtained from the linear regression analysis that correlates LRUO to both PCI and IRI 
showed a very good correlation. This model can be used to determine the Libyan road pavement index.

3. IRI value can be determined quickly, and economically using smartphone applications as it showed good correlation with PCI.

4. The proposed mathematical model needs to be calibrated using data from different roads.

\section{AUTHORS CONTRIBUTION}

We encourage authors to submit an author statement outlining their individual contributions to the paper using the relevant roles:

1- Conception or design of the work (25\% for all authors)

2- Data collection and tools (first author $100 \%$ )

3- Data analysis and interpretation ( $25 \%$ for all authors)

4- Investigation (25\% for all authors)

5- Methodology (25\% for all authors)

6- Project administration (25\% for all authors)

7- Software (25\% for all authors)

8- Supervision (second, third and fourth authors 100\%)

9- Drafting the article (25\% for all authors)

10- Critical revision of the article. (25\% for all authors)

11 - Final approval of the version to be published $(25 \%$ for all authors

The corresponding author is responsible for ensuring that the descriptions are accurate and agreed by all authors.

\section{REFERENCES}

[1] S. A. F. Al-Arkawazi, "Flexible Pavement Evaluation: A Case Study," Kurdistan J. Appl. Res., vol. 2, no. 3, pp. 292-301, 2017.

[2] F. Hong and D.-H. Chen, "Effects of surface preparation, thickness, and material on asphalt pavement overlay transverse crack propagation," Can. J. Civ. Eng., vol. 36, no. 9, pp. 1411-1420, 2009.

[3] A. L. I. Mohamed and A. L. I. Zaltuom, "EVALUATION PAVEMENT DISTRESSES USING PAVEMENT CONDITION INDEX," UNIVERSITY OF DIPONEGORO Semarng, 2011.

[4] A. Okine and O. Adarkwa, "Pavement Condition Surveys - Overview of Current Practices," Pavement Index Methods, vol. 19716, no. 302, pp. 1-71, 2013.

[5] M. D. Daniel L. Stacks, P.E., Director, "Pavement Manual Notice 20182," no. July, 2018, [Online]. Available: http://onlinemanuals.txdot.gov/txdotmanuals/pdm/pdm.pdf.

[6] Hasanuddin, A. Setyawan, and B. Yulianto, "Evaluation of Road Performance Based on International Roughness Index and Falling Weight Deflectometer," in IOP Conference Series: Materials Science and Engineering, 2018, vol. 333, no. 1, doi: 10.1088/1757899X/333/1/012090.

[7] Y. U. Shah, S. S. Jain, D. Tiwari, and M. K. Jain, "Development of Overall Pavement Condition Index for Urban Road Network," Procedia - Soc. Behav. Sci., vol. 104, pp. 332-341, 2013, doi: 10.1016/j.sbspro.2013.11.126.

[8] O. Elmansouri, A. Almhroog, and I. Badi, "Urban transportation in Libya: An overview," Transp. Res. Interdiscip. Perspect., vol. 8, p. 100161, 2020.
[9] S. M. Piryonesi and T. E. El-Diraby, "Examining the relationship between two road performance indicators: Pavement condition index and international roughness index," Transp. Geotech., vol. 26, p. 100441, 2021, doi: 10.1016/j.trgeo.2020.100441.

[10] A. A. Elhadidy, S. M. El-Badawy, and E. E. Elbeltagi, "A simplified pavement condition index regression model for pavement evaluation," Int. J. Pavement Eng., vol. 0, no. 0, pp. 1-10, 2019, doi: 10.1080/10298436.2019.1633579.

[11] M. S. Abed, "Development of Regression Models for Predicting Pavement Condition Index from the International Roughness Index," J. Eng., vol. 26, no. 12, pp. 81-94, 2020, doi: 10.31026/j.eng.2020.12.05.

[12] R. Psalmen Hasibuan and M. Sejahtera Surbakti, "Study of Pavement Condition Index (PCI) relationship with International Roughness Index (IRI) on Flexible Pavement.," MATEC Web Conf., vol. 258, p. 03019, 2019, doi: $10.1051 /$ matecconf/201925803019.

[13] W. N. Carey Jr and P. E. Irick, "The pavement serviceability performance concept,” Highw. Res. Board Bull., no. 250, pp. 40-58, 1960.

[14] W. R. Hudson, R. Haas, and E. Perrone, "Measures of pavement performance must consider the road user," 2015.

[15] S. S. Tehrani, L. C. Falls, and D. Mesher, "Road users' perception of roughness and the corresponding IRI threshold values," Can. J. Civ. Eng., vol. 42, no. 4, pp. 233-240, 2015.

[16] Z. A. Kadhim and Z. A. Z. Mahdi, "Evaluation of Asphalt Pavement Distresses in Main Roadways in Al-Diwaniyah City," J. Univ. Babylon Eng. Sci., vol. 26, no. 1, pp. 72-80, 2018.

[17] J. S. Miller and W. Y. Bellinger, "FHWA, Distress Identification manual for the Long-Term Pavement Performance Program. Report FHWAHRT-13-092," no. May, p. 142, 2014.

[18] P. M. Y. Shahin, Ph.D., Micro PAVER Development. 2004.

[19] T. Hanson, C. Cameron, and E. Hildebrand, "Evaluation of low-cost consumer-level mobile phone technology for measuring international roughness index (IRI) values," Can. J. Civ. Eng., vol. 41, no. 9, pp. 819827, 2014, doi: 10.1139/cjce-2014-0183.

[20] “The AASHO Road Test Report 5:Pavement Reserch," 1962.

[21] K. Hall and C. Muñoz, "Estimation of Present Serviceability Index from International Roughness Index," Transp. Res. Rec. J. Transp. Res. Board, vol. 1655, no. 1, pp. 93-99, Jan. 1999, doi: 10.3141/1655-13.

\section{Title Arabic:}

تطوير نموذج حسابي لتقييم حالة الرصف الاسفلتي للطرق الليبية

\section{Arabic Abstract:}

يعتبر تقييم حالة الرصف خطوة مهمة جدا للحفاظ على العمرالإفتراضي

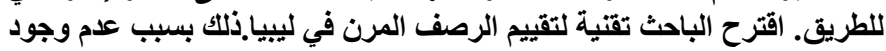

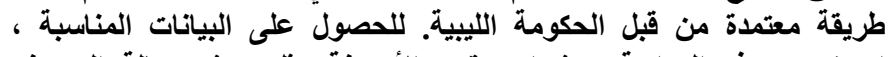

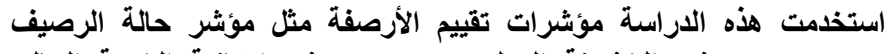

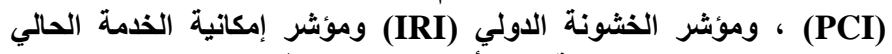
(PSI)

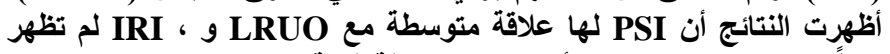

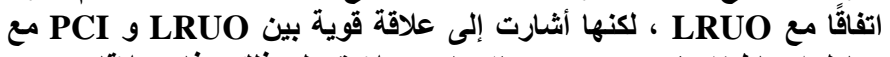

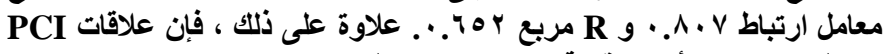

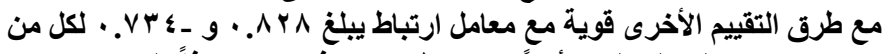

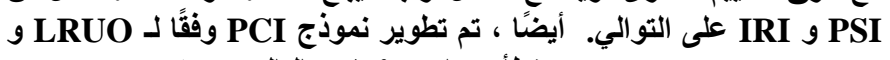

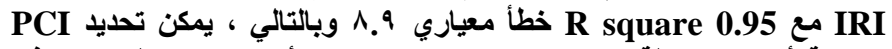

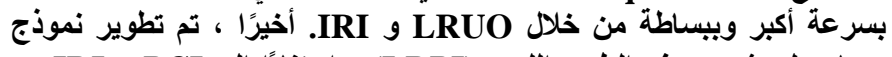
حسابي لمؤشر رصف الطرق الليبي (LRPI) ، استنادًا إلى الى د

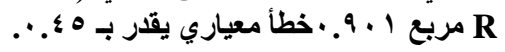

